\title{
ГЕНЕТИЧЕСКИЕ АСПЕКТЫ ФОТОСИНТЕЗА АРОМАТИЧЕСКИХ СОРТОВ ТАБАКА И ПУТИ ОПТИМИЗАЦИИ СЕЛЕКЦИИ: КОЭФФИЦИЕНТ ФОТОСИНТЕТИЧЕСКОЙ ПРОДУКТИВНОСТИ
}

\author{
В.А. Маркарян \\ Национальный аграрный университет Армении \\ margaryan_vardan@yahoo.com
}

\section{СВЕДЕНИЯ}

Ключевые слова:
табак,
фотосинтетическая
продуктивность,
комбинационная способность,
диаллельный анализ,
корреляции,
селекция

\begin{abstract}
АННОТАЦИЯ
В четвёртой статье серии подведены результаты генетического анализа коэффициента фотосинтетической продуктивности (КФП) семи сортов табака сортотипа Самсун. Подтверждено, что гибридам $\mathrm{F}_{1}$ свойственен промежуточный тип наследования признака, что проявляется в основном воздействием аддитивных генов рецессивного характера, чем и объясняются расхождения между показателями КФП и $\hat{\mathrm{g}}_{\mathrm{i}}$.

Обоснована важность КФП как ценного фотосинтетического маркера при создании гибридных комбинаций с помощью улучшенного фотосинтетического аппарата.

Результатами исследования выделены ценные сорта и перспективные гибриды для селекции и предложены конкретные рекомендации по оптимизации всех её звеньев.
\end{abstract}

\section{Введение}

Проблема повышения ароматичности и качества сырья отечественных сортов типа Самсун путём интенсификации фотосинтетического аппарата с применением генетико-селекционных методов является актуальной для современной генетики фотосинтеза табака. Особо ценны и перспективны те фотосинтетические признаки, которые характеризуются как высокой генотипической обусловленностью, стабильностью и повторяемостью их уровня по годам, так и прочной сопряжённостью с основными компонентами продуктивности и качества урожая.
Исключительно важно, что среди этих признаков выявляются и такие, которые можно использовать в роли маркеров для идентификации генотипов с повышенной фотосинтетической активностью по фенотипам.

Проведённые многими авторами исследования по поиску таких маркеров преследовали цель не только сократить очевидные трудовые и финансовые расходы и повысить эффективность селекции, но и сделать весь продукционный процесс управляемым и пригодным к моделированию всех его звеньев. Поскольку этот процесс подразумевает выполнение многочисленных 
и трудоёмких аналитических работ с вовлечением как исходных сортов, так и множества генотипов из расщепляющихся гибридных популяций, физиологами, генетиками и селекционерами проводились исследования по поиску морфологических признаков, имеющих высокую сопряжённость как с признакамимаркерами, так и с отдельными составляющими фотосинтетической активности растений.

В обзорной статье М.И. Зеленского обстоятельно анализируются результаты собственных исследований и экспериментальные данные других авторов, обобщённые в 70 статьях по 11 важнейшим фотосинтетическим признакам у 6-ти групп разных возделываемых культур, включающих 22 вида и сорта, в том числе и 5 генотипов табака. Среди исследуемых образцов в отдельных случаях выявлена высокая степень вариабельности. Так, у образцов табака как важнейший фотосинтетический признак анализированы показатели интенсивности фотосинтеза, которые варьировались в пределах 9.013.0 мг $\mathrm{CO}_{2} /$ дм² $^{2}$ час, что хорошо согласуется с нашими данными (В.А. Маркарян, 2019). У некоторых фрорм в фенотипической изменчивости отмечается значительная доля генотипической вариансы, которой объясняется многолетняя стабильность уровня исследуемых признаков и высокие показатели наследуемости. Представленные автором данные по улучшению отдельных фотосинтетических характеристик путём отбора и с учётом комбинационной способности сортов по отдельным признакам привели его к выводу о реальной возможности селекционного улучшения этих признаков и получения интенсивных форм с устойчиво усиленной фотосинтетической активностью (М.И. Зеленский, 1980).

В своём знаменитом докладе на 42-ом Тимирязевском чтении А.Т. Мокроносов, касаясь роли фотосинтетических признаков, полностью поддержал вышеотмеченные выводы и предложения М.И. Зеленского, характеризовав их как перспективные в генотипической интенсификации фотосинтетического аппарата. Резюмируя свои исследования, автор выделил 21 морфофизиологический показатель листа (показатели мезоструктуры), назвав их полезными для учёта при реализации селекционных программ, связанных с фротосинтетической продуктивностью, в частности, в процессе подбора, оценки исходного материала и разработки идеотипа сорта. С этой целью он разработал методику изучения этих показателей и оценки функциональной активности фотосинтетического аппарата. Отмечается, что предложенная им морфофизиологическая концепция мезоструктуры фротосинтетического аппарата является полезным инструментом при эколого-физиологических исследованиях, применение которого оправдало себя при решении разных задач.
В связи с ограниченным применением результатов исследований по фотосинтезу в селекционной практике автором подчёркивается важность повышения их прикладного характера и перспективность оптимизации морфофизиологического типа растений с целью создания идеатипа сорта в конкретных условиях как биотехнический проект работы селекционера.

Проблема ухудшения качества продукции при росте урожаев (что за последние 70-80 лет повсеместно наблюдается в табаководстве и очень характерно для ароматических сортов) связывается автором с реакцией роста, фотосинтеза и специфического биосинтеза на применяемую агротехнику, направленную на оптимизацию условий возделывания, на что сильнее реагируют первые два процесса, а более консервативным оказывается биосинтез и отложение ценных веществ в запас, удельная концентрация которых в хозяйственно ценной части урожая снижается. При этом меняется структура ростовых процессов, изменяются морфофрункциональные корреляции и донорно-акцепторные связи в целом растении. Ввиду актуальности указанной проблемы, А.Т. Мокроносов её разработку считает самостоятельной областью физиологии целого растения, которая позволяет создать основу для управления как величиной, так и качеством урожая (А.Т. Мокроносов, 1983).

Подводя итог результатов исследований по поиску и использованию маркерных признаков в процессе идентификации генотипов по фенотипам и созданию базы для разработки параметров идеотипа сорта, приходим к выводу, что успех в этой работе связан с комплексной оценкой исходных форм и гибридных популяций по важнейшим генетическим параметрам не только по компонентам продуктивности, но и по морфофизиологическим признакам.

\section{Материалы и методы}

Основные критерии подбора родительских форм Самсун 47 (C-47), Самсун 55(C-55), Самсун 36 (С-36), Самсун 224 (С-224), Самсун 27 (С-27), Самсун Бафра (С.Б.), Самсун Маден (С.М.) и полученные по диаллельной схеме скрещивания прямые гибриды, их ботаническое описание и генетико-селекционная целесообразность использования в данной работе, а также модели и методы генетико-математического анализа подробно изложены в первой статье данной серии (В.А. Маркарян, 2019). Следует также отметить, что предложенный нами Коэффициент фотосинтетической продуктивности (КФП) вычисляется как соотношение показателей интенсивности фотосинтеза и дыхания: КФП=ИФ/ИД. 


\section{Результаты и анализ}

Результаты дисперсионного анализа средних значений сортов и гибридов, а также варианс общей и специфической комбинационной способности (ОКС, СКС) по КФП доказывают высокую достоверность этих показателей и существующие различия между ними. Очевидна также определяющая роль аддитивных и неаддитивных эффектов генов в генетической детерминации признака. При этом аддитивный вклад генов более чем в 5.7 раз превосходит неаддитивные эффекты (таблица 1).

Проведённым анализом установлена высокая достоверность как усреднённых значений анализируемого признака сортов и гибридов, так и их эффректы ОКС $\left(\hat{\mathrm{g}}_{\mathrm{i}}\right)$ и варианс эффректов ОКС $\left(\sigma^{2} \mathrm{G}_{\mathrm{i}}\right)$ и СКС $\left(\sigma^{2} \mathrm{~S}_{\mathrm{i}}\right)$, а также обнаруженные различия внутри указанных параметров.

Таблица 1. Дисперсионный анализ средних значений признака и комбинационной способности сортов и гибридов табака по КФП*

\begin{tabular}{|l|c|c|}
\hline $\begin{array}{c}\text { Источник } \\
\text { изменчивости }\end{array}$ & $\begin{array}{c}\text { Число степеней } \\
\text { свободы }\end{array}$ & $\begin{array}{c}\text { Средний квадрат } \\
\text { МS признака }\end{array}$ \\
\hline Общий & 83 & 131.90 \\
\hline Повторность & 2 & 15.12 \\
\hline Вариант & 27 & $364.49^{\star *}$ \\
\hline Случайный & 54 & 19.94 \\
\hline ОКС & 6 & $4534.20^{\star *}$ \\
\hline СКС & 21 & $788.99^{* *}$ \\
\hline Ошибка & 54 & 6.65 \\
\hline
\end{tabular}

${ }^{* *} P<0.001$
По существу высокий показатель КФП является индикатором, свидетельствующим о наличии у селектируемых форм способности проявлять высокую фотосинтетическую продуктивность. У исходных сортов высокими показателями КФП выгодно отличаются как высокоурожайный сорт С-47, так и низкопродуктивные сорта С-27, С.М. и С.Б., а его низким показателем сорта С-55, С-224 и С-36. Интересно отметить, что выявленные различия внутри этих групп сортов были высокодостоверными (таблица 2).

Анализ наследования КФП в $\mathrm{F}_{1}$ свидетельствует о преобладании промежуточного типа наследования, который из 21 гибрида наблюдается у 13-ти. У одного гибрида (С.Б.ХС.М.) выявляется полное доминирование родительской формы с высоким, а у 3-х (С-27хС.М., С-27xС.Б., С-47xС-36) - с низким показателями признака. Позитивный гетерозис отмечается лишь у гибрида С-224xC-27, а негативный - у 3 гибридов (С-47хС.Б., С-47хС.М., С-47xС-27). Примечательно, что у всех гибридов с негативным гетерозисом, как правило, материнским сортом выступает С-47, а отцовские формы имеют близкие с ним показатели признака и, что интересно, все они характеризуются наивысшими показателями КФП. Заслуживает особого внимания гетерозисный гибрид С-224xС-27, который следует включить в селекционную работу не только в целях гетерозисной селекции, но и как ценный исходный материал, поскольку его родители обладают высоким показателем как КФП, так и $\hat{\mathrm{g}}_{\mathrm{i}}$ и, что важно, у них признак проявляется преимущественно действием аддитивных генов, которые, соответственно, превосходят неаддитивные эфффекты от 2.7 до 5.3 раз. Помимо этого перспективность данного скороспелого гибрида заключается и в том, что у него высокая фотосинтетическая продуктивность проявляется в наиболее благоприятный период вегетации, что позволяет сфор-

Таблица 2. Результаты анализа комбинационной способности по КФП*

\begin{tabular}{|l|l|l|l|l|l|l|l|l|l|l|}
\hline \multicolumn{1}{|c|}{ Сорт } & C-47 & C-55 & C-36 & C-224 & C-27 & C.5. & C.M. & $\hat{\mathbf{g}}_{\mathrm{i}}$ & $\boldsymbol{\sigma}^{\mathbf{2}} \mathbf{G}_{\mathrm{i}}$ & $\boldsymbol{\sigma}^{\mathbf{2}} \mathbf{S}_{\mathrm{i}}$ \\
\hline C-47 & $\mathbf{3 6 . 8 2}$ & 12.92 & 12.32 & 32.16 & 20.68 & 13.20 & 17.23 & 20.420 & 416.578 & 96.248 \\
\hline C-55 & 12.92 & $\mathbf{1 1 . 2 2}$ & 15.58 & 14.47 & 16.39 & 20.58 & 15.81 & 13.159 & 172.741 & 12.424 \\
\hline C-36 & 12.32 & 15.58 & $\mathbf{1 9 . 6 0}$ & 19.22 & 28.30 & 29.53 & 28.54 & 19.398 & 375.888 & 20.621 \\
\hline C-224 & 32.16 & 14.47 & 19.22 & $\mathbf{1 2 . 8 9}$ & 60.72 & 15.81 & 30.66 & 22.318 & 497.671 & 182.241 \\
\hline C-27 & 20.68 & 16.39 & 28.30 & 60.72 & $\mathbf{3 3 . 2 5}$ & 28.12 & 29.66 & 28.052 & 786.510 & 148.922 \\
\hline C.Б. & 13.20 & 20.58 & 29.53 & 15.81 & 28.12 & $\mathbf{3 0 . 2 7}$ & 34.55 & 22.549 & 508.042 & 49.123 \\
\hline C.M. & 17.23 & 15.81 & 28.54 & 30.66 & 29.66 & 34.55 & 33.16 & 24.990 & 624.112 & 25.025 \\
\hline
\end{tabular}

$H C P_{0.01}=10.098 ;\left(\hat{g}_{\mathrm{i}}-\hat{g}_{\mathrm{j}}\right)=0.974$;

*Таблица составлена автором. 
мировать ароматическое сырьё с высокими курительными достоинствами

Важность роли аддитивных генов выявлена также в генетической детерминации высоких показателей признака и $\hat{\mathrm{g}}_{\mathrm{i}}$ у сортов С.Б. и С.М., чем и объясняется целесообразность их использования в селекционной практике. Следует также отметить решающий вклад аддитивных генов в обусловленность признака у сортов C-47, C-55 и C-36, что было доказано соотношениями показателей $\sigma^{2} \mathrm{G}_{\mathrm{i}}$ и $\sigma^{2} \mathrm{~S}_{\mathrm{i}}$, которые равнялись, соответственно: 4.3, 13.9 и 18.2 .

Сопоставлением показателей признака сортов и $\hat{\mathrm{g}}_{\mathrm{i}}$ зафриксирован ряд соответствий. Так, высоким показателям признака у сортов С-27, С.М. и С.Б. соответствуют такие же значения $\hat{\mathrm{g}}_{\mathrm{i}}$, а низким показателям признака у сортов С-55 и С-224 аналогичные показатели $\hat{\mathrm{g}}_{\mathrm{i}}$. Наряду с этим отмечен также ряд несоответствий. Например, несмотря на то что сорт C-47 имеет наивысший показатель признака,

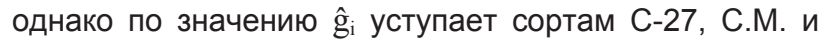
С.Б. и, что интересно, эта разница была существенной. Интересно также отметить, что несмотря на то что сорта С-27 и С.М. имеют примерно равные значения КФП, однако первый сорт по показателю $\hat{\mathrm{g}}_{\mathrm{i}}$ достоверно превосходит второй.

Отмеченные несоответствия объяснимы при учёте результатов полигенного анализа сортов, который проводился по модели Хеймана, что предъявляет некоторые ограничения к исходным сортам. Так, в генетической детерминации признака отсутствия неаллельных генных взаимодействий (эпистаза) доказана однородностью разности $\mathrm{W}_{\mathrm{r}}-\mathrm{V}_{\mathrm{r}}$ с помощью критерия $\mathrm{t}$, который при $\mathrm{n}=5$ числу степеней свободы имеет недостоверное значение. Показателями коэффициентов корреляции $\mathrm{r}_{\mathrm{Wr} / \mathrm{Vr}}(+0.399)$ и регрессии $\mathrm{b} \mathrm{wr} / \mathrm{Vr}$ $(+0.192)$ между $\mathrm{W}_{\mathrm{r}}$ и $\mathrm{V}_{\mathrm{r}}$, а также расположением линии регрессии на графике зависимости доказывается её существенное различие от линии единичного наклона.

При генетической обусловленности признака характерно сверхдоминирование, что подтверждается как расположением линии регрессии, которая пересекаетет ось $\mathrm{OW}_{\mathrm{r}}$ ниже начала координат, так и значением показателя средней степени доминантности - $\left(\hat{\mathrm{H}}_{1} / \mathrm{D}\right)^{1 / 2}$, величина которой больше единицы (рис.).

На грасрике регрессии в расположении сортов наблюдается примечательная картина. Максимальное накопление доминантных полигенов отмечается у сорта C-55, который характеризуется минимальными показателями КФП и $\hat{\mathrm{g}}_{\mathrm{i}}$ и находится в нижнем конце линии регрессии. Отмеченными полигенами насыщены также генотипы сортов С-36, С.М., С.Б. и С-47, имеющие в основном высокие показатели признака и $\hat{\mathrm{g}}_{\mathrm{i}}$ и, что интересно, по этим же показателям они существенно отличаются, но сгруппировались по соседству с сортом C-55 с некоторым сдвигом к центру графика регрессии. По сути у изученных сортов важность значения доминантных полигенов отмечена в детерминации как высоких, так и низких показателей КФП. Однако сорт С-224 резко отодвинут к верхней части графика и поэтому его сравнительно низкие показатели признака и $\hat{\mathrm{g}}_{\mathrm{i}}$ обусловлены действием преимущественно рецессивных полигенов.

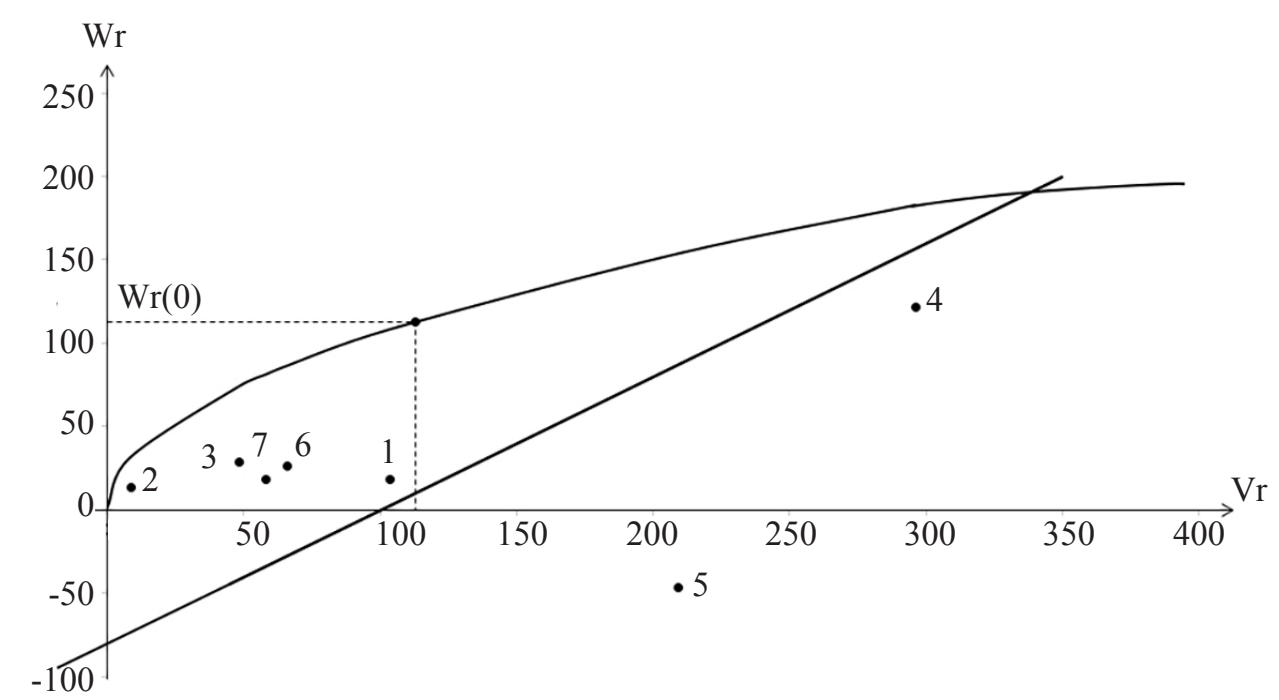

Рис. График $\left(\mathrm{W}_{\mathrm{r}}, \mathrm{V}_{\mathrm{r}}\right)$ по признаку «Коэфффициент фотосинтетической продуктивности» 1.С-47; 2. С-55; 3.С-36; 4. С-224; 5. C-27; 6. C.E.; 7.C.M. 
По сути причиной вышеотмеченных несоответствий между показателями КФП и $\hat{\mathrm{g}}_{\mathrm{i}}$ является меняющийся баланс доминантных и рецессивных полигенов в проявлении признака. При увеличении в этом балансе доли рецессивных полигенов возрастают расхождения между указанными параметрами и возникает ситуация, когда по анализируемому признаку лучший сорт С-47 не обладает самым высоким показателем $\hat{\mathrm{g}}_{\mathrm{i}}$. Однако, как было показано, у этого сорта по сравнению с расположенными по соседству другими сортами в указанном балансе значительно увеличена доля рецессивных полигенов, проявляющих аддитивный характер, следовательно по сравнению с теми, у которых отмечен более высокий показатель $\hat{\mathrm{g}}_{\mathrm{i}}$, в селекционном плане он более перспективен, и для реализации его генетического потенциала требуется скорректировать методику ведения селекции в расщепляющихся гибридных популяциях. Поэтому на раннем этапе селекции перспективных гибридов C-47xC-224 и C-224xC-27 с целью исключения потерь ценных генотипов следует произвести больший объём выборок, поскольку генотипы с высокими показателями КФП могут выщепляться в более поздние сроки $\left(\mathrm{F}_{3}-\mathrm{F}_{5}\right)$, а также необходимо повременить жёсткую отбраковку селекционного материала и реализовать её в старших гибридных поколениях.

Что касается перспективного гибрида С.Б.хС.М., у которого генотип насыщен доминантными генами, имеющими аддитивный характер, то тут высока вероятность появления ценных особей в ранних поколениях $\left(\mathrm{F}_{2}-\mathrm{F}_{4}\right)$ и, следовательно, сроки отбраковки необходимо установить в этих популяциях. Рекомендуется также указанный гибрид вместе с комбинациями С-36хС.М. и С-36хС.Б. использовать и в гетерозисной селекции, поскольку у последних высокие показатели признака управляются доминантными полигенами. Решающая роль доминантных генов в проявлении признака в сторону возрастания подтверждается также коэффициентом корреляции между показателем признака $\left(\mathrm{x}_{\mathrm{p}}\right)$ и суммой варианс и коварианс $\left(\mathrm{W}_{\mathrm{r}}+\mathrm{V}_{\mathrm{r}}\right)$, которая имеет отрицательный знак $\left(\mathrm{r}_{\mathrm{Xr} / \mathrm{Wr}+\mathrm{Vr}}=-0.277 \pm 0.192\right)$. Указанный вывод подтверждается также вычисленным параметром $\mathrm{F}_{\mathrm{r}}$, характеризующим направление доминирования для каждого сорта, которое у большинства сортов имеет положительный знак и равняется от 66.99 (С-27) до 348.18 (С-55). Исключением был сорт С-224, у которого $\mathrm{F}_{\mathrm{r}}=-442.99$, что доказывает преобладающую роль рецессивных генов в увеличении признака, что было отмечено выше. Таким образом, в результате проведённого диаллельного анализа выявлена роль действия разных групп генов в проявлении признака и выделены перспективные гибриды для выведения ароматических сортов и гетерозисных гибридов табака с конкретными рекомендациями по оптимизации селекционной работы.

Эффрективность указанной работы обеспечивается также учётом коррелятивных связей между селектируемыми признаками, поскольку в генотипе гибридов, как правило, возникает необходимость сочетать хозяйственно полезные признаки, определяющие количество и качество табачного сырья, которые взаимосвязаны как положительными, так и отрицательными корреляциями. Поэтому в практической селекции пренебрежение этими связями приводит к неоправданным потерям не только ценных генотипов, но и фринансовых ресурсов и времени, и как следствие - такая работа безрезультатна. В этом плане генетические корреляции $\left(\mathrm{r}_{\mathrm{g}}\right)$ по сравнению $\mathrm{C}$ фенотипическими $\left(\mathrm{r}_{\mathrm{p}}\right)$ и паратипическими $\left(\mathrm{r}_{\mathrm{e}}\right)$ часто имеют разнонаправленный характер и посему их знания представляют особую ценность. Ввиду этого вычисляли коэфффициенты указанных корреляций между КФП и структурными составляющими продуктивности и качества табачного сырья (Таблица 3).

Таблица 3. Генетические $\left(\mathrm{r}_{\mathrm{g}}\right)$, френотипические $\left(\mathrm{r}_{\mathrm{p}}\right)$ и паратипические $\left(\mathrm{r}_{\mathrm{e}}\right)$ корреляции КФП $\mathrm{c}$ другими количественными признаками****

\begin{tabular}{|c|c|c|c|}
\hline \multirow{2}{*}{ Признак } & \multicolumn{3}{|c|}{ Коэффициенты корреляций } \\
\hline & $\mathbf{r}_{\mathrm{g}}$ & $\mathbf{r}_{\mathbf{p}}$ & $\mathbf{r}_{\mathrm{e}}$ \\
\hline КФП х КЛ ${ }^{1}$ & $-0.234^{*}$ & $-0.233^{*}$ & $-0.241^{*}$ \\
\hline КФП х ДЛ² & $-0.474^{* * *}$ & $-0.451^{* * *}$ & -0.128 \\
\hline КФП х ШЛ & $-0.472^{\star \star \star}$ & $-0.451^{* * *}$ & -0.117 \\
\hline КФП х ВР 4 & $-0.415^{\star * *}$ & $-0.396^{* * *}$ & 0.058 \\
\hline КФП х ППЦ 5 & $-0.380^{* * *}$ & $-0.363^{* *}$ & 0.052 \\
\hline КФП х ТЛ ${ }^{6}$ & $-0.363^{\star *}$ & $-0.262^{*}$ & $0.237^{*}$ \\
\hline КФП х $\mathrm{CCB}^{7}$ & $-0.297^{\star *}$ & -0.189 & 0.062 \\
\hline КФП х УСЛ ${ }^{8}$ & $-0.404^{* * *}$ & $-0.395^{* * *}$ & $-0.212^{*}$ \\
\hline КФП х ИФ9 & $0.426^{\star \star *}$ & $0.442^{* \star *}$ & $0.705^{\star \star *}$ \\
\hline КФП х ИД ${ }^{10}$ & $-0.521^{\star * *}$ & $-0.501^{* * *}$ & -0.172 \\
\hline КФП х X«a+b» ${ }^{11}$ & 0.123 & 0.092 & -0.004 \\
\hline КФП х X«а» ${ }^{12}$ & 0.118 & 0.088 & -0.013 \\
\hline КФП x X«b»» ${ }^{13}$ & $0.348^{* *}$ & 0.094 & 0.001 \\
\hline
\end{tabular}

${ }^{*} P<0.0{ }^{* *} P<0.01{ }^{* * *} P<0.001$

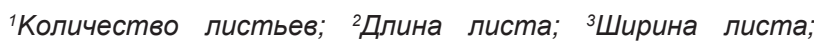
${ }^{4}$ Высота растений; ${ }^{5}$ Период посадки-цветения; ${ }^{6}$ Темп листообразования; '7Соержание сухого вещества; ${ }^{8}$ Урожай сухих листьев; '

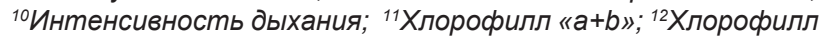
«а»; ${ }^{13}$ Хлорофилл «b».

`Таблца составлена автором. 
Анализ вычисленных коэффрициентов корреляций у 13-и пар признаков показывает, что у 11-и пар обнаружены достоверные корреляции, из коих у 7-и пар (КФПхИД, КФПхДЛ, КФПхШЛ, КФПхИФ, КФПхВР, КФПхУСЛ, КФПхППЦ) они сильные, у 3-х пар (КФПхТЛ, КФПхХ«b», КФПхССВ) - средние, и у одной пары (КФПхКЛ) - слабые корреляции. У отмеченных пар в 9-и случаях показатели $\mathrm{r}_{\mathrm{g}}$ превосходят $\mathrm{r}_{\mathrm{p}}$ и $\mathrm{r}_{\mathrm{e}}$, лишь в одном случае (КФПхИФ) он уступает их, а у одной пары (КФПхКЛ) - он слабее чем $\mathrm{r}_{\mathrm{e}}$. Из вышеуказанных 11-и пар положительные корреляции зафиксированы в 2-х (КФПхИФ, КФПхХ«b») случаях, а в остальных установлены отрицательные корреляции, из которых в 5-и случаях такое направление характерно всем 3-м коэфрфициентам и у 4-х пар - только $\mathrm{r}_{\mathrm{g}}$ и $\mathrm{r}_{\mathrm{p}}$. Интересно отметить, что анализируемый признак, как правило, слабо коррелирует с содержанием зелёных пигментов и только в одном случае (КФПхX«b») $r_{g}$ имеет средний существенный показатель, а у остальных пар отмечены несущественные коэфрфициенты корреляций. Как правило, во всех случаях $\mathrm{r}_{\mathrm{g}}$ по сравнению $\mathrm{c} \mathrm{r}_{\mathrm{p}}$ имеет более высокие показатели, хотя оба они имеют идентичную направленность. При их значимых показателях у $r_{\mathrm{e}}$ отмечены слабые $и$ недостоверные корреляции, которые в 6-и случаях имеют противоположный знак и лишь в 2-х случаях (КФПхКЛ, КФПхИФ) показатели $\mathrm{r}_{\mathrm{e}}$ превосходили их значения.

Таким образом, у анализируемых сортов и гибридов табака установлены сильные положительные корреляции КФП с ИФ и содержанием хлорофилла «b», и, что важно, в корреляциях у первой пары признаков наряду с генетическими факторами весьма значима роль влияния окружающей среды, что подтверждается очень высоким и значимым показателем $\mathrm{r}_{\mathrm{e}}$, а у второй пары отмечается его полное отсутствие. Существуют прочные отрицательные корреляции между КФП и важнейшими составляющими продуктивности (КЛ, ДЛ, ШЛ, ВР, ППЦ, УСЛ, ТЛ, ССВ), а также ИД, что позволяет совмещать в генотипе перспективных сортов и гибридов умеренный урожай с высокой ароматичностью и курительными достоинствами сырья благодаря увеличению интенсивности фротосинтеза табачного растения.

\section{Заключение}

Проведённым генетическим анализом подтверждается важность совокупного действия аддитивных и неаддитивных эффектов генов в проявлении КФП, при котором определяющая роль принадлежит аддитивным генам. У гибридов $\mathrm{F}_{1}$ преобладает промежуточный тип наследования, хотя зафиксированы также явления позитивного и негативного гетерозиса, а также случаи полного доминирования родительской фрормы с высоким и низким показателями признака.

В генотипе изученных сортов равнозначные показатели признака обусловлены действием разных полигенов с их различными соотношениями.

При изменении этого баланса в сторону накопления рецессивных полигенов возрастают расхождения между показателями КФП и $\hat{\mathrm{g}}_{\mathrm{i}}$, что чревато недооценкой генетического потенциала селекционного материала и вероятностью его неоправданной утраты. Именно поэтому с учётом основных критериев идеотипа сортотипа Самсун предлагается дифференцировать оценку генетического потенциала исходных форм по комбинационной ценности, выявлять роль разных генетических систем в детерминации признака и корректировать методику ведения селекции в расщепляющихся гибридных популяциях. С учётом результатов комплексной оценки селекционного материала по указанным критериям выделены перспективные сорта и гибриды с конкретными предложениями по подбору исходного материала, отбору и браковке потомства гибридов. Так, в целях селекции на фотосинтетическую продуктивность рекомендуются использовать сорта С.М., С.Б., С-27 и С-47, а также гибриды С-47xС-224, С-224xC-27, С-36xС.М., С-36хС.Б., С.Б.хС.М. Последние четыре гибрида с успехом можно использовать также в гетерозисной селекции, для которой получены аналоги материнских сортов с ЦМС.

Вычисленные у исходных сортов и перспективных гибридов сильные положительные корреляции КФП с ИФ и отрицательные - с ИД и важнейшими компонентами продуктивности позволяют за счёт увеличения интенсивности фотосинтеза получить высокоароматичные линии с умеренным урожаем и востребованным качеством сырья. Следовательно, КФП является ценным фотосинтетическим маркером при создании гибридных комбинаций с улучшенным фотосинтетическим аппаратом и важнейшим параметром идеотипа сорта Самсун.

\section{Литература}

1. Зеленский М.И. Селекционно-генетический аспект изучения фотосинтетической деятельности культурных растений // В кн.: Труды по прикладной ботанике, генетике, селекции. - Т.67. -Вып. 2. -Л., 1980. - С. 38-47.

2. Маркарян В.А. Генетические аспекты фотосинтеза ароматических сортов табака и пути оптимизации селекции: интенсивность фоотосинтеза // Аграрная наука и технология. Национальный аграрный университет Армении. - N (66)2. - 2019. - С. 76-81.

3. Мокроносов А.Т. Фотосинтетическая функция и целостность растительного организма // 42-е Тимирязевское чтение. - М.: Наука, 1983. - 64 с. 


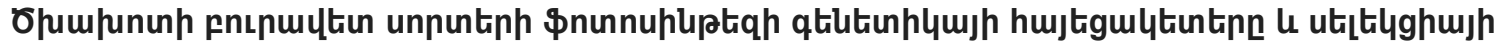

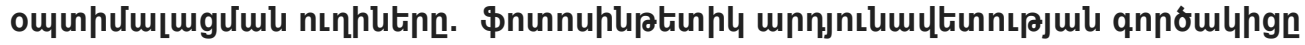

\section{4.u. Umpquinjur}

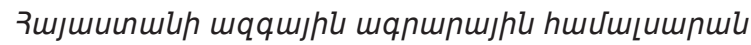

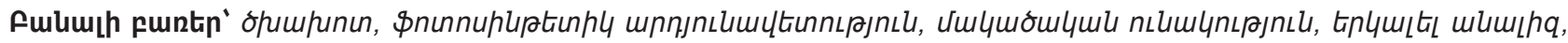

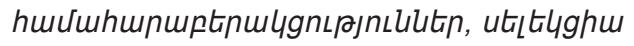

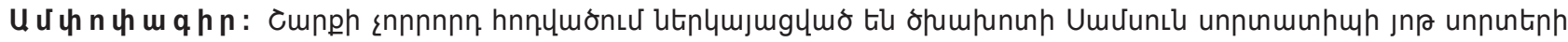

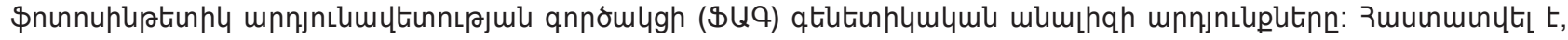

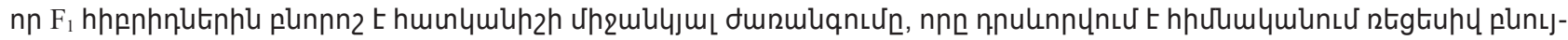

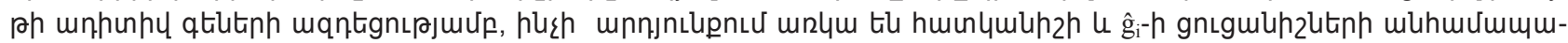
unuupumunıpjnLultin:

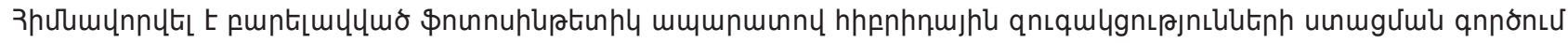

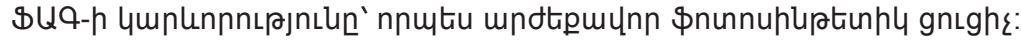

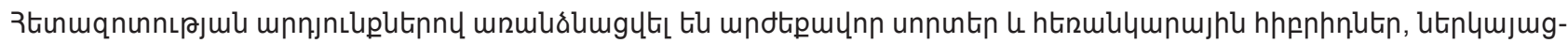

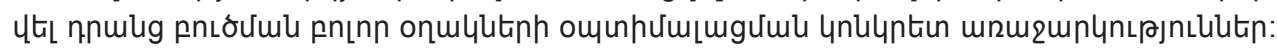

\section{Genetic Aspects of Photosynthesis of Aromatic Tobacco Varieties and the Optimization Ways of Selection: Coefficient of Photosynthetic Productivity}

\section{V.A. Margaryan}

\section{Armenian National Agrarian University}

Keywords: tobacco, photosynthetic productivity, combining ability, diallel analyses, correlations, selection

Abstract. The results of genetic analysis on the coefficient of photosynthetic productivity (CPP) in seven varieties of Samsun tobacco are summed up in the fourth article of the series. It has been confirmed that in the hybrids of $F_{1}$ an intermediate inheritance of the trait prevails, which is mainly manifested by the impact of recessive additive genes leading to incompatibility in the indices of $\hat{g}_{i}$ and the mentioned trait.

The significance of CPP as a valuable photosynthetic index in the creation of hybrid combinations with an improved photosynthetic apparatus has been justified.

In the result of the study, valuable varieties and perspective hybrids have been identified and specific recommendations on optimizing all breeding stages have been introduced. 